\title{
From the Outside Looking In Reactions to the Better Public Services Report
}

Policy Quarterly invited the leaders of some key external organisations that are stakeholders of the public sector to comment on the Better Public Services report. The following comprises their views.

\section{The Institute of Public Administration New Zealand (IPANZ) is a voluntary, not-for-}

profit organisation committed to promoting improvements in public policy and in administration and management across New Zealand's public sector, in both central and local government. It works by providing a platform for debate on emerging and controversial issues and a forum for networking, ideas, learning and development. The current president of IPANZ is Len Cook, who, amongst other appointments, was the Government Statistician from 1992 to 2000, and this is his response.
The Better Public Services report is for the public sector of New Zealand. It identifies a range of issues that are important and brings a legitimacy and vigour to thinking about public management that we have not seen for over 20 years. IPANZ welcomes this. The issues raised by the review are difficult to challenge, although the emphasis placed on some matters and the solutions offered are cause for debate. This is reinforced by the way ministers have decided to act on them.

The willingness by ministers to question key elements of our arrangements in New Zealand is a welcome development. It is important to acknowledge that we may have only scratched the surface of how 
deeply we need to think about what we need to change, if we are to maintain our standard of living while capturing the acceleration in benefits that information technology and science are opening up for us. This has to be done in the face of global economic uncertainty, environmental risks and opportunities, and huge shifts in the age structure of the population across all regions.

In recognising that independent agencies, operating autonomously, could not deliver effectively the public services that the New Zealand public has come to expect, the new super-ministries, lead independent entities in quite a few other domains, including local government. The National Health Board set up in 2009 has been one important response to the need for managing the health network. What is not clear is how the Better Public Services initiative is drawing on the experiences we already have in complex networks, and it is surprising that the health sector is not heavily involved in the leadership groups we now have. As a consequence, the focus on systems called for in the BPS report is not yet strong enough, but what we now have is a significant turning point which will

\section{The emphasis on leadership needs to more strongly recognise that high-quality, experienced staff can drive the public sector forward ...}

departments and central agency role review remind us of the time prior to 1988, when large ministries provided, albeit inconsistently, a degree of value network leadership that was generally not understood or recognised by many of us at the time.

Such a rethink will inevitably bring new relationships with business and community organisations. We need to quickly sharpen our capacity to lead the value networks vital to us, and determine the nature of those relationships. Without strong oversight and transparency in such relationships citizens will never be sure which commercial, community or individual interests are the greater beneficiaries of the many public-private partnership-like arrangements that have become the norm for governments of all hues. Kiwisaver, private prisons and schools, and the broadband development subsidies typify these new relationships.

In the quest for the most efficient long-term accumulation and use of personal and national resources, we now need to question whether it makes sense to accept the autonomous operation of some 2,500 schools, nearly 40 publicly funded universities, polytechnics and wānanga, 20 district health boards, several energy companies, and manifold bring a sensible focus for amalgamations that are surely inevitable.

Without a rich understanding of the place in each value network of the leadership, knowledge, people, structures and systems that are a platform for change, we risk destroying these assets through continuing the past series of poorly formulated restructuring of agencies. The emphasis on leadership needs to more strongly recognise that high-quality, experienced staff can drive the public sector forward, and that developing people needs to extend to all staff, especially as we face huge experience loss as the baby-boom generation retires. For example, a quick analysis of the demographic profile of nurses in New Zealand should trigger much deeper concern than has so far been apparent. Without sector-wide leadership we leave a lot of important things to chance. The public sector is still without a contemporary organisation model that will see it into the future.

Governments of all types have periodically sought to find ways of ensuring that the public sector as a whole has some sort of overall sense of direction. We have yet to achieve this, despite efforts ranging from specifying detailed outputs to articulating high- level strategic goals set by political preferences. We have few beacons that are based on well-researched, commonlyrecognised national goals, and so at an agency level performance expectations remain dominated by short-term cost efficiency.

The consequent frequent assessment of performance has led to high degree of inwardly-oriented process monitoring. Wide-ranging monitoring and independent review of policy outcomes is neither facilitated nor resourced. We most likely need less frequent but very tough assessments of our situation. In general, the outcomes of the many Performance Improvement Framework reviews highlight serious concerns regarding strategic directions across the public sector. We have yet to recognise that the expectations on those in public service are only partially observed in outputs, outcomes or results measures. Public servants may now be clearer about what is not expected. Public servants are creatures of the law, the courts and of ministerial direction, but many of the public pressures that lead to new statute or new policy or ministerial direction are first faced at the sharp end of public service - at the front line, at a time when personal judgement, taking risks and testing authority makes sense in terms of natural justice, the public interest or human rights.

The new results areas announced in accordance with the BPS report bring direction, but we need an analytical basis for them, to provide some balance to the extent to which each new government is prepared to maintain them (or throw them out) as part of its own mix of priorities. Without a thoughtful understanding of significant system and market failures, periodic revisions to such political enthusiasms will drive a new set of priorities, with little understanding of where the next priority will come from. With such a narrow set of explicit targets, in the face of a wide range of judgements required at the coal face by public servants, citizens may well believe that the public sector is clearer about what is not their role than what is. 


\section{ANGOA, the Association of Non- Governmental Organisations of Aotearoa, is a network of organisations from across}

the range of NGOs in Aotearoa New Zealand, including national, regional and local groups. Member organisations are active in the areas of health, education, international development, human rights, arts, culture and heritage, recreation and sports, social services, family budgeting, hospice care, disability, conservation and the environment, ethnicity, child and youth support, women, mental health, aged care, refugee support, family planning, support of prisoners and their families, and injury prevention. Marion

Blake is the current chair of ANGOA and, together with the ANGOA coordinator, Dave Henderson, provided this comment.

$\mathrm{T}$ he government has outlined its desire to deliver better public services to New Zealanders which will deliver results across ten areas. Whilst the focus is on the public sector, the effects will also be significant for how community organisations currently work, and could have far-reaching impact in developing new responses to some thorny issues. There is plenty to work on as the problems we face are complex and beyond what is possible using the traditional public sector, single-agency response. Many in the community sector are up for a new approach.

In the context of tight financial constraints the aim to get traction on some tough social issues will, as senior ministers have commented, depend on tapping into the wealth of experience and knowledge that lies in community agencies. So a betterperforming public sector is applauded by community organisations, which for many years have highlighted the growth of territorial government departments which call for innovation yet act out of stagnation, talk about collaboration yet operate in isolation. Achieving the results means not only changing the the Crown; but increasingly there are opportunities to explore new solutions that lie in the field of entrepreneurial connections between business and social enterprise, community agency and the government. This will call for new models of collaboration, investment and governance. These new sets of relationships have the potential both to deliver the Better Public Services agenda and improve the system.

Commissioning, purchasing, contracting, procurement and others are the terms applied to the numerous processes whereby the government passes on money to a third party to pay for a service; this is an area targeted by BPS. 'Best sourcing' adds a new one, but also challenges the government agencies to market-test their roles and look for cost-effective options, providing an opportunity for efficient community agencies to deliver.

Making chief executives accountable for achieving results and not just for managing a department or agency means new behaviours, which means that public sector leaders will need more flexibility and imagination. Changes will also be required in the State Sector Act and the Public Finance Act, which are currently often seen as the basis of current practices. Taking out layers of compliance and bureaucracy is one of the aims of proposed legislative changes. This will release pressure on community agencies, as contract negotiation, management, compliance and audit have become critical detractions from service delivery.

Delivering outcomes has to be a real driver of change and not just a policy statement. It is a chance to refocus the whole system. The fear of the community sector is that government agencies will individually and independently seek to achieve their part of the results that are sought and not go for the more complex cross-agency approach. They would thereby hit the target but miss the point.

Community organisations have long resisted the pressure to work in the same kind of silos as government agencies do, and can bring more lateral and innovative cross-agency thinking to 
the table. Targets and action plans will not be effective if they are developed by government agencies behind closed doors, with the same people asking the same questions and giving each other the same answers. The sector contributes $4.9 \%$ of GDP (including volunteer hours), similar to the contribution of the construction industry. Volunteer labour in 2010 was estimated to be 270 million hours, which translates into $\$ 3.5$ billion. Volunteering is not restricted to the community sector. A lot of core central and local government work is also actively supported by volunteers: for example, the coastguard, police, prisons, and search and rescue. The sector is a significant contributor to the social and economic health of New Zealand.

From a multi-story office in Wellington the community sector can look messy, full of duplication, undifferentiated and hard to link up with. In reality the sector is well organised and has a structure which is not immediately apparent. A set of umbrella groupings link organisations with a like focus, such as sports, continuing education, social services or disability, and each has a set of links that extend out into the national community. Each constantly gathers and disseminates information and innovative ideas from around the country - information and ideas that are potentially highly useful to government agencies, if they can recognise the value in terms of their ability to deliver their own outcomes.

By these organisations the vision of the Better Public Services report is hugely welcomed because it is the way the sector prefers to work. Community organisations have long been aware that the narrow outputs they were contracted to provide in the past might or might not help achieve outcomes. That disconnect is a result of the 1980 os public service reforms and has been perpetuated over subsequent decades.

For the new results, targets and action plans to be real, agencies of government need to see themselves as firmly anchored in and belonging to society, rather than somehow sitting above or off to one side. Non-profit organisations are usually better at understanding community issues, relating to and supporting at-risk groups, and delivering actual services and support than public organisations. Public organisations dealing with complex social issues therefore need to be open to grassroots innovation, learning and collaborative opportunities within the community. Linking with that is not as hard as it may seem, and will make successful results that much more certain.

\title{
The PSA, the Public Service Association/ Te Pukenga Here Tikanga Mahi, is New
}

\author{
Zealand's largest union, representing 58,00o workers in
} central government, state-owned enterprises, local councils, health boards and community groups. The PSA is an important and influential stakeholder which seeks policies that improve public services and the working conditions of those who deliver them. The following comment comes from Brenda Pilot, one of the two national secretaries of the PSA.

$\mathrm{T}$ PSA's immediate reaction to the Better Public Services Advisory Group Report (the BPS report) was that the public service, beset by job cuts and constant restructuring, would find it hard to deliver on the government's aspirations for better public services. For every good idea in the report, and there are plenty, there are 'buts', and these 'buts' could well undermine the vision.

Looking at the positive aspects of the report, it is good to see a break with the past. The State Sector Act and the operation of the public service since 1988 have often stood in the way of effective services that respond to the real-life needs of citizens. The BPS report suggests positive ways to remedy the problems caused by a fragmented public service. Some of these good ideas are finding their way into the proposed amendments to the core public sector legislation, according to the policy backgrounder recently released by the government. These include technical changes that will assist in cross-departmental and crossvote initiatives and moves to strengthen sector-wide functional leadership.

A greater focus on results, supported by better and simpler ways to work across departments and across votes - these are welcome changes. So are the moves to focus on operational excellence and more citizen-centric services. All of us who work in or with the state sector want a more responsive and flexible approach to meeting client needs.

The greater focus on innovation and especially on continuous improvement is another positive. The trick will be making innovation possible in a system that has risk-aversion bedded deep in its psyche. That risk-aversion stems first and foremost from ministers, who have zero tolerance for public service failure.

A change in management culture from command and control to high engagement will also be needed to allow genuine innovation to flourish. Both the research and the direct experience of workers are unambiguous: the most productive and innovative workplaces are those where staff have a high degree of control over their work, where there are high-trust relationships between managers and staff, and where the union is involved. While there are pockets of this kind of culture in the public service, it is far from the norm.

The current reality of public services is one of constant and draining 
restructurings, budget cuts, loss of opportunity and low morale. This poses both political and management challenges to realising the recommendations of the report.

It is a concern that so little of the BPS report focuses on the workplace and the capability needed for better public services. This area urgently needs attention in the implementation work programme, and it will not be enough to simply give more power to the State Services Commission and to focus only on second- and third-tier managers. This will not deliver 'the right culture and capability'.

It is worth noting that we already have a very flexible public service workforce, and measures that do nothing to slow or reverse the trend towards more fixedterm and contracted roles and the greater use of consultants will not build the capacity needed to meet the challenges of delivering better services.

The 'value for money' aspects of the BPS report have far less to recommend them and foreshadow hard times ahead for public servants, involving more change and more job losses. The greater movement towards shared services is an example of this, and seems likely also to involve privatisation of many of these functions.

Privatisation is also strongly envisaged in the 'best sourcing' idea, where agencies would be required 'to market-test all of their roles, functions and services by looking to see where it would be more cost-effective to out-source to nongovernment organisations, private sector or other third-party providers'. This idea has all the hallmarks of Treasury zealotry and it may be that the government has little political will to carry it through, other than in selected areas such as property management. Such an idea requires more thought than simply consideration of fiscal drivers.

There is little sense of the 'public good' in the report. Beyond doing things more efficiently and effectively, there is no vision of better public services as the foundation of a better, more equal society. Setting a series of process-oriented targets does not equate to that vision.

\section{There is little sense of the 'public good' in the report. Beyond doing things more efficiently and effectively, there is no vision of better public services as the foundation of a better, more equal society.}

Technology challenges are laid out in the report. In principle the idea of standardising information across the state services makes sense. So does making transactional services available online. But the report envisages more than this and talks of accelerating the shift to online channels. While many New Zealanders like to - and are able to access government services online, there is still a digital divide in New Zealand. People who have no or limited access to technology are among the most frequent users of government services.

The difficulties of replacing community offices with call centres are already apparent. This does not mean we should shy away from looking for the maximum potential to leverage off technology to deliver better public services, but it does mean a realistic and practical approach is needed. No one should be lulled into thinking this is a cheap option. Many government information systems are massive and the costs of developing, installing and keeping them up to date are significant.

The Better Public Services report does well to signal the need for a more joinedup and responsive state sector and to identify some of changes in work culture necessary to deliver it. Delivering on the vision of the report will require the goodwill and the contribution of those who work to deliver public services. No one should underestimate the challenge that this represents or the gains that can be made if this is successfully achieved. 